\section{Cross-Border Power Trade to Support Resilience}

\section{Introduction}

Cross-border power trade can support goals such as improved grid resilience, increased energy access, reaching renewable energy targets, and increasing economic development. This fact sheet explains how cross-border trade can be a potential technical solution to support resilience. Designing power systems that enhance resilience across neighboring countries can be challenging and complex, but also highly beneficial. Cross-border power trade that enhances system resilience can be enabled by some of the approaches and actions presented in this fact sheet. Figure 1 presents three proposed subregional electricity markets in Southeast Asia that could connect power systems across borders. In this case, effectively designed markets would support increased integration of renewables, energy security, and grid reliability and resilience in the Association of Southeast Asian Nations (ASEAN) region.

\section{What Is Power Sector Resilience?}

The ability to anticipate, prepare for, and adapt to changing conditions and withstand, respond to, and recover rapidly from disruptions to the power sector through adaptable and holistic planning and technical solutions (Hotchkiss et al. 2018).

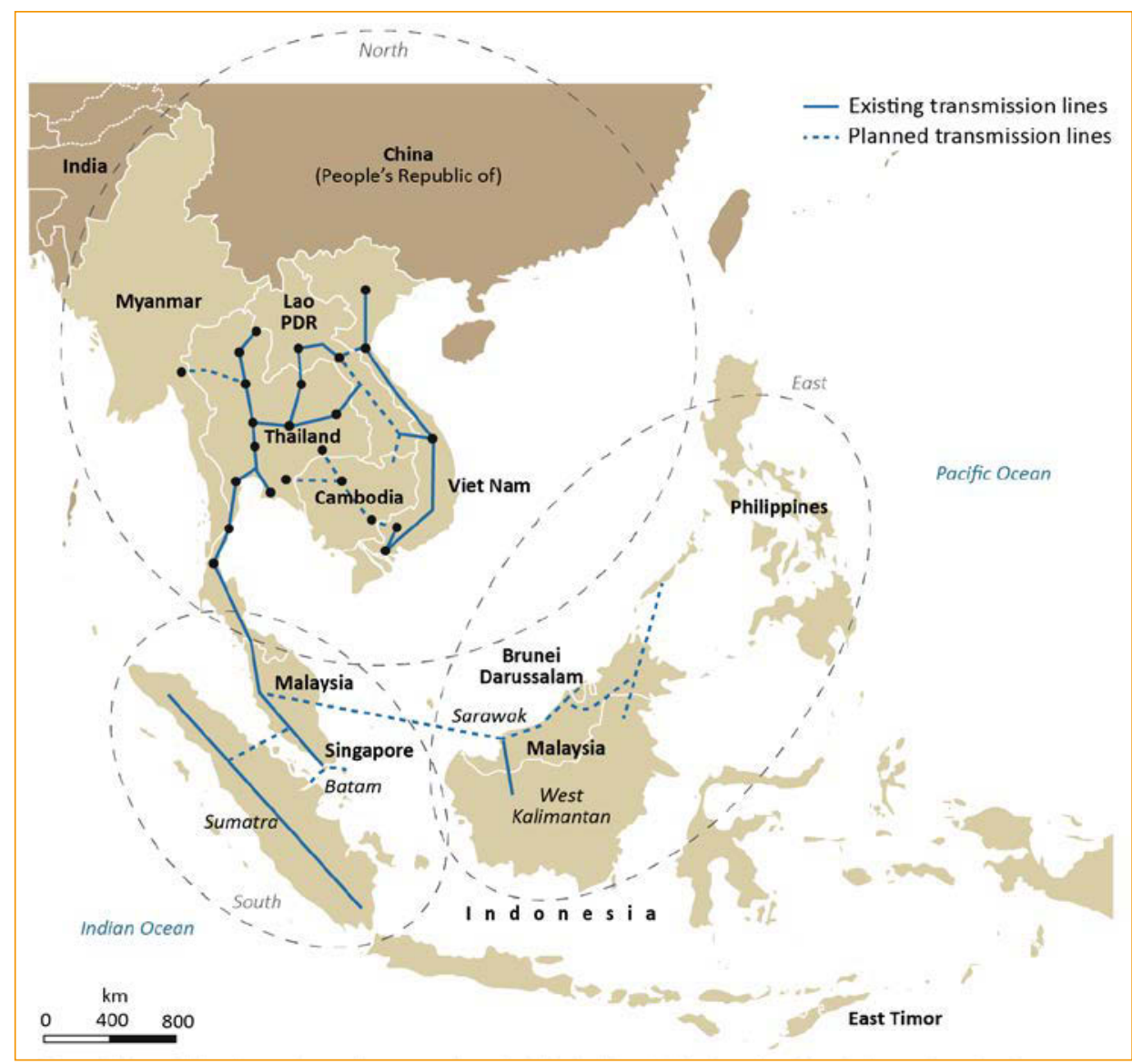

Figure 1. Three proposed subregional electricity markets in ASEAN Illustration from International Energy Agency

Many other power sector technical solutions to support resilience are detailed in the Resilient Energy Platform fact sheet series, available at https://resilient-energy.org/training-and-resources/ fact-sheets.

\section{Cross-Border Power Trade to Enable Resilience}

Depending on the form, cross-border power trade can involve different degrees of coordination between system operators and utilities. A fully integrated wholesale market, for example, might cover a number of interconnected countries served by a single system operator.
Alternatively, a utility in one country may sell services to a utility in a neighboring country through a series of bilateral contracts. A country may also host a tenant generator that connects directly to a utility in a neighboring country.

Enhancing Resilience through Diversification

Diversity of a power generation portfolio can relate to spatial location, generation resources, and water use.

Spatial diversity-A more spatially diverse generation portfolio may better withstand location-specific extreme 


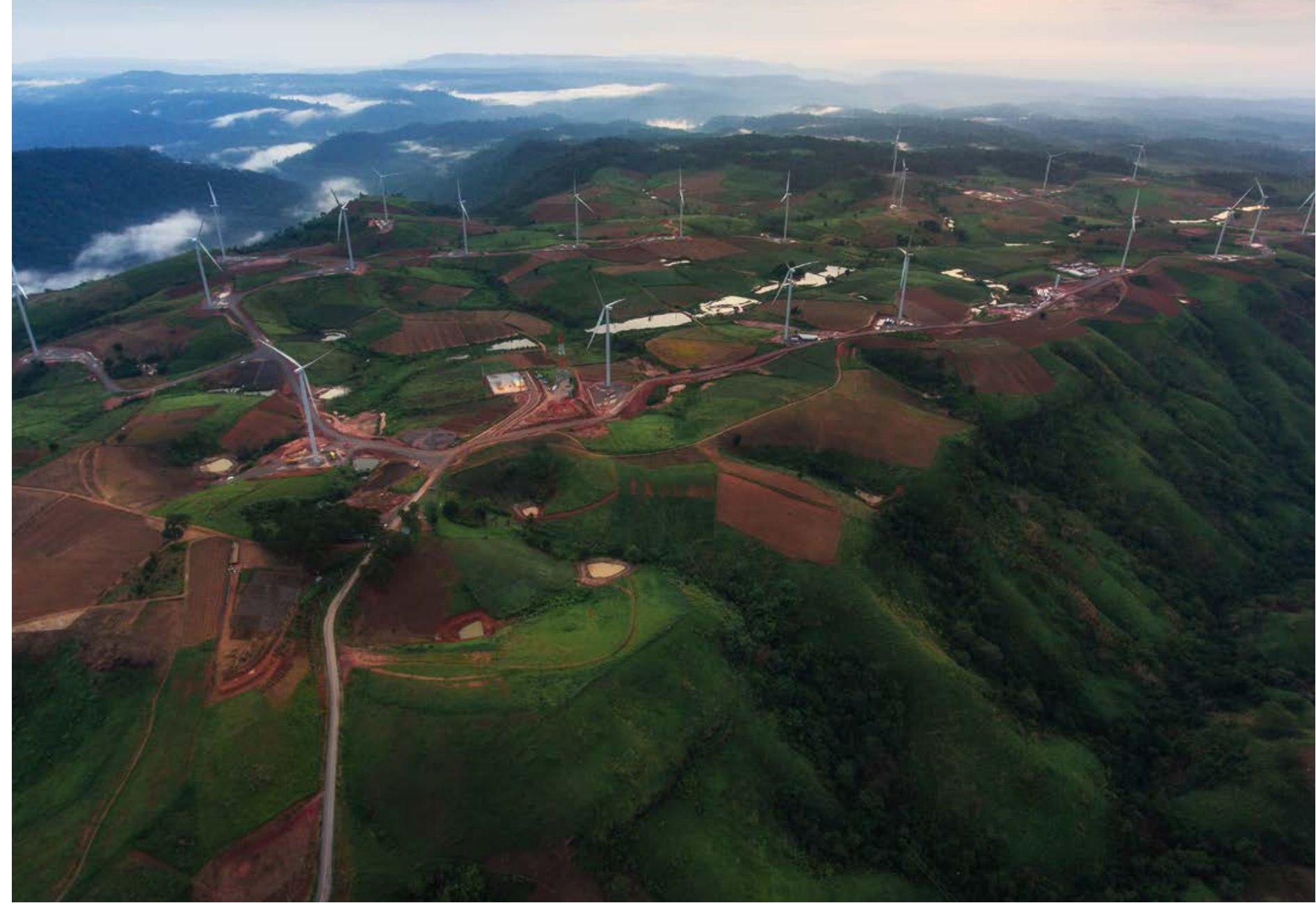

Aerial view of wind turbines on a mountain in Phetchabun, Thailand Photo from iStock 1182629174

events (such as natural disasters or cyberattacks) as more resources, in different geographic areas, may be available to provide power, especially for critical

\section{Box 1. Regulatory Framework for Cross-Border Power Trade in Europe}

A regulatory framework is necessary to ensure all types of cross-border electricity trade between two or more countries are clearly defined, framed, and protected. Europe has experienced an increase in cross-border electricity transmission capacity and flows over the past few decades, partly due to the European internal energy market. This increase has led to the need for and the development of European Union-wide network codes and guidelines implemented by the European Commission. These regulations govern all cross-border electricity market transactions, as well as system operations for accessing the network for cross-border electricity exchange. facilities. At the same time, interconnecting with systems across a broader geographic area may make it necessary to identify threats and vulnerabilities, as well as resilience solutions across that broader geographic range (e.g., across borders). Thus, when considering cross-border power trade, it is crtitical to undertake a vulnerability assessment that analyzes the proposed interconnected system holistically. This key step is further detailed in the "Identifying Threats and Vulnerabilities across Countries" section of this fact sheet.

Resource/fuel diversity-Diverse generation portfolios can provide a smoothing effect across resources, allowing for improved overall reliability and opportunities for scaled-up integration of variable renewable energy sources, such as wind and solar power, by reducing the overall relative variability and uncertainty (Cox et al. 2017). Bringing in additional renewable resources can also allow countries to decrease dependence on fossil fuels that can be susceptible to price volatility. Diverse generation portfolios in relation to water use (e.g., that reduce dependence on hydro) can also support resilience through decreasing vulnerability to climatic changes or other events that might impact precipitation or water supply.

\section{Enhancing Resilience Through System Flexibility}

System flexibility enables the matching of electricity supply with demand and can be particularly important in supporting resilience. Key measures on the supply and demand side can lead to greater flexibility including implementation of storage, improving flexibility of conventional generation, renewable energy curtailment, actions to enable responsive load, and expansion of transmission. When developing cross-border power trade agreements, particularly with high levels of renewables, flexibility measures can be included to improve overall reliability and resilience of the system. 
Building on the information above, cross-border power trade that enables resilience requires a detailed understanding of resource potential, power system vulnerabilities, and opportunities for partnership across nations. With this in mind, current key actions to support resilient cross-border power trade are detailed below.

\section{Assessing Renewable Energy Resource and Energy Efficiency Potential}

Renewable energy can play an integral role in supporting resilience. Assessing renewable energy resource potential across countries can be an important first step in resilient cross-border power trade, particularly where countries have different and complementary renewable energy endowments.

The renewable energy resources available to a country depend on geography and topography. Geospatial analysis can identify areas where renewable resources could have the highest mutual benefit in supporting power supply (based on land use factors, distance to transmission, and so on). The Southeast Asia Renewable Energy Data Explorer provides one example of a geospatial tool that could support assessment of renewable energy potential at a regional level. Access the tool here: https://www.re-explorer.org/ launch.html.

Additionally, generation and load mismatch can be addressed through load management. Countries can also consider further assessment of energy efficiency and demand response options to provide power system flexibility and resilience through planned load growth and control. Improving the prediction and management of load can reduce stress on a system overall, within or across borders.

Finally, cross-border trade is significantly influenced by the policies and regulations of all national parties involved. It is likely that new regulatory frameworks will need to be implemented by the partner
Box 2. Expansion of Cross-Border Power Trading in South Asia

The countries of South Asia have been exploring paths to increased crossborder power trade for several years under USAID's South Asian Regional Initiative for Energy Innovation (SARI/ EI). More recently, India has begun to explore major reforms in its wholesale electricity market that could facilitate economically efficient exchanges among Indian states and with its neighbors. For Nepal, cross-border electricity trade (CBET) offers an opportunity to export hydropower generation it does not need during the monsoon season, and to import supplemental power during the dry season to prevent load shedding. For India, access to Nepal hydropower has the potential to reduce its reliance on expensive foreign coal to generate power. For both countries, access to additional generation resources can shorten the recovery time after disruptions to the grid.

Bangladesh has a memorandum of understanding with Nepal to purchase Nepal hydropower. Diminishing natural gas reserves and growing demand are creating near-term pressure on Bangladesh's power system, which is not

nations to enable electricity trade. The timelines for implementing new regulations or national policy should be considered when developing cross border energy trade programs. Box 1 presents a regulatory framework developed in Europe to support cross-border power trade.

\section{Identifying Threats and Vulnerabilities Across Countries}

In planning for resilient cross-border power trade, it is critical to identify threats and vulnerabilities to the power systems in each country-both natural threats (i.e., hurricanes) and non-natural threats (i.e., cyberattacks). Threats and related vulnerabilities of the power system will inform interconnection decisions and actions to enable resilience. For example, synchronously connected with India or Nepal. Plans to expand the DC connection between Bangladesh and the Indian state of West Bengal would increase the amount of power that could flow to Bangladesh from India and Nepal.

A 2019 study of South Asia indicates that institutional issues might be at least as important as physical infrastructure in realizing the full benefits of CBET (McBennett et al. 2019). Institutional challenges can include trade barriers, high cross-border tariffs, and the lack of harmonized standards for scheduling and operations. One key finding was that physically adding more hydropower in Nepal would in fact do little to increase CBET unless the institutional barriers were addressed.

India and Nepal are using energy banking as an interim CBET measure. Under this arrangement, excess hydropower production in Nepal during the monsoon season is exported to India, with the volume credited against future flows from India to Nepal during the dry season when hydropower production is low. In July 2019, Nepal provided as much as 200 MW to India in accordance with the banking agreement (Nepal24hours.com 2019).

a country may consider threats related to hydropower (e.g., precipition changes) in another nation before interconnecting. As another example, transmission lines built at high elevations and within areas that are hard to access (e.g., mountainous regions of Nepal) may make maintenance and safety difficult for line workers. If avalanches and landslides are common in those same areas, the system will either need to be located in a different, lower-risk area, or technological solutions, such as burying lines or hardening of transmission line towers and poles, may be necessary. Conducting a vulnerability assessment across countries will allow decision makers to identify key threats and vulnerabilities that will inform the planning process and technological solutions, as well as the broader decision to proceed with interconnection or not. If the countries do proceed with 
interconnection, it is also critical to clearly articulate roles and responsibilities to address power outages that may occur and have an impact across nations.

\section{Planning for Collaboration}

Understanding the goals, needs and motivations across countries for cross-border trade can inform institutional arrangements and detailed planning. Several key planning and design steps are necessary to enable cross-border trade. Some of these may include detailed planning for border interconnections and related investments, development of new regulatory bodies (e.g., the Agency for the Cooperation of Energy Regulators in Europe [ACER 2019]), establishment of regional power producers, design of competitive regional markets (see

Box 3. Cross-Border Collaboration for Power Sector Resilience in Malawi and Mozambique

Malawi has historically operated as an islanded grid in southeast Africa. The country's network, made of 2,395 km of transmission lines and 39 substations, supplies power across interconnected communities in Malawi and to limited cross-border towns in Mozambique and Zambia (ESCOM 2015). The islanded grid has been unable to keep up with rapidly growing demand in Malawi--with a current installed capacity at $250 \mathrm{MW}$ and an estimated need to serve a peak demand of approximately $351 \mathrm{MW}$ (Club of Mozambique 2019). This suppressed energy growth has amplified energy security and sovereignty concerns with frequent power outages. These outages are related both to under-capacity issues and changing climate and urbanization scenarios. For example, in early 2019, heavy rainfall events triggered runoff that carried urban waste into waterways and clogged hydro plants. This resulted in a reduction of nearly $165 \mathrm{MW}$ of power and triggered power outages across the country. ${ }^{1}$ These power cuts magnify economic vulnerability of Malawi through reduction in productivity. Additionally, lack of available power has broadly
Resources on page 6 for examples), and design of harmonized policies, regulations, and codes (USAID). These areas are not considered in detail in this document, but vast literature is available on these topics. As one example, see: http:// documents.worldbank.org/curated/ en/707091468183843171/Institutionalarrangements-for-the-promotion-ofregional-integration-of-electricitymarkets-international-experience. Box 2 presents a collaborative approach to supporting cross-border power trade in South Asia.

\section{Technical Requirements for Interconnecting Transmission Infrastructure}

The power systems of countries can be interconnected in different ways, primarily

hampered economic development and diversification in Malawi, as only $11 \%$ of the population currently has access to electricity services (The World Bank). The U.S. Agency for International Development emphasizes that compounding issues of undersupply and increasing energy access could lead to a 400-MW power deficit in Malawi by 2025 if interconnection to surrounding countries is not realized (USAID 2018).

In 2010, the government of Malawi recognized that increasing power availability and quality--as well as accomplishing energy access for all-would require more power than the grid could supply. The government also recognized that national economic resilience was directly tied to the availability of adequate power to drive productivity. In response, the nation began negotiating with Mozambique on the development of a cross-border interconnection with the South African Power Pool. The first phase of this interconnection, which secured funding in early 2019, will see Malawi import 50 MW of power across a 400-kV line from Mozambique (Club of Mozambique 2019). This new transmission line is expected to be completed by 2021. synchronously or asynchronously (with the link use of power electronics). The potential threats that one power system can cause another will depend on the type of interconnection between the two systems, the way the two power systems and the cross-border flows are controlled, and the protection schemes of both power systems. Similarly, these will also define the potential support (in terms of energy supply, frequency response, and voltage support) that a cross-border interconnection may provide to a system under normal operating conditions or after a disturbance (e.g., weather extreme event, man-made physical or cyberattack, or generation or transmission outage.

High voltage direct current (HVDC) transmission is used when interconnecting asynchronous power systems between
This project represents a major step in increasing power system resilience in Malawi through provision of additional electric resources, particularly during times of grid stress. But this also does not represent a fail-safe solution to grid reliability and a full solution to chronic power undersupply. In 2019, Hurricane Idai devastated much of Malawi and parts of Mozambique and was quickly followed by Hurricane Kenneth, with similar impacts. Windspeeds at landfall were in excess of $100 \mathrm{mph}$ and damaged the transmission lines that supply power across southeast Africa (Resnick 2019). Power outages persisted for more than a week throughout Malawi, Mozambique, and South Africa due to the damaged transmission lines (Jenner 2019; Resnick 2019). These storms significantly impacted the entire power system of Malawi-including the interconnection transmission lines. The storms and their associated impacts further hampered power service delievery in Malawi. As the system is rebuilt, it will be vital to consider a variety of resilience solutions-in addition to the reconstruction of the interconnection transmission line--to ensure future power delivery.

1 https://www.bnef.com/core/ news/688717?e=News\%20Watch:sailthru 


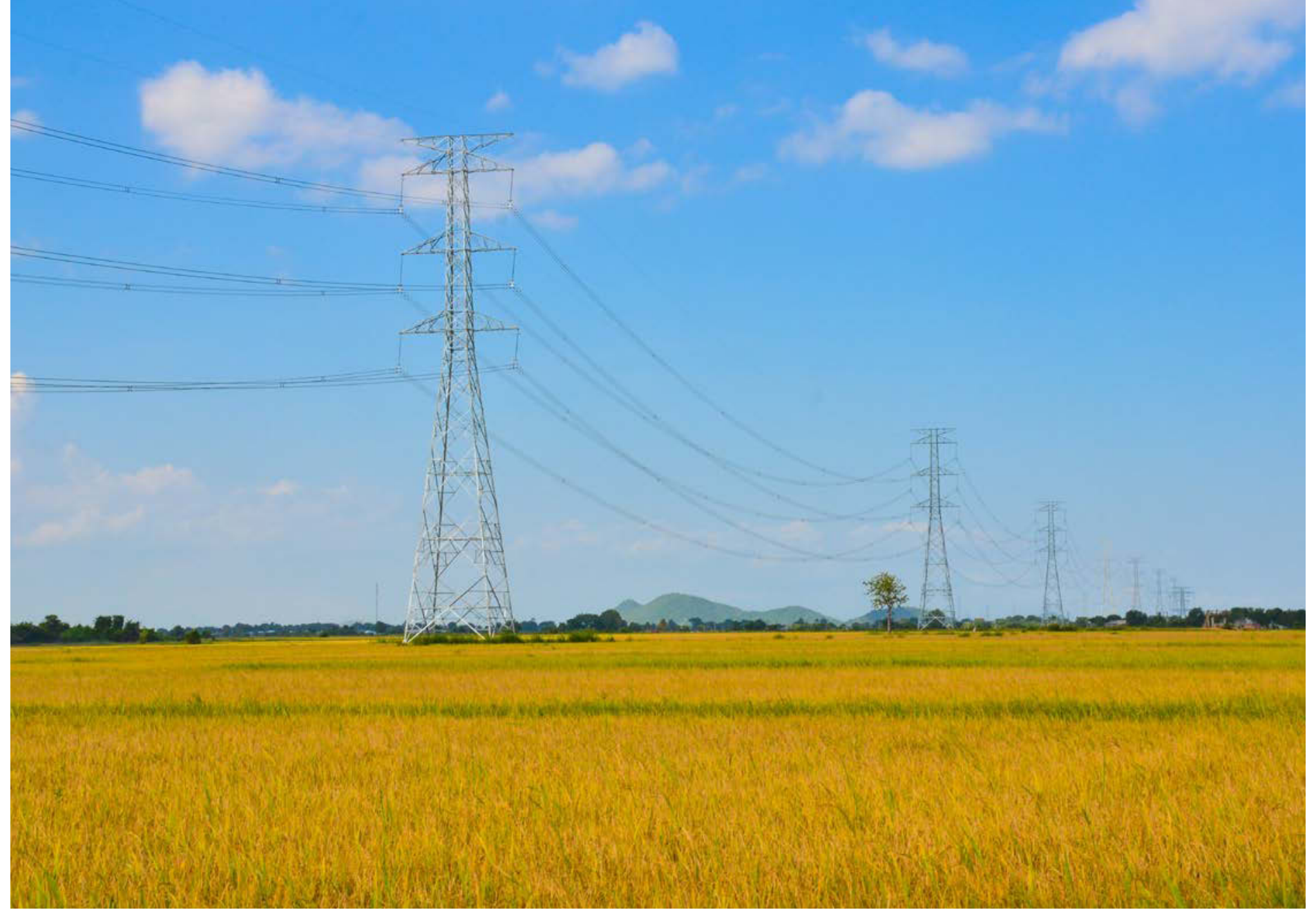

Rice field in the Mekong Delta, Vietnam Photo from iStock 499596494

countries (land-based or submarine), or even within the same country (e.g., Japan). In some cases, back-to-back HVDC converters are used to establish power flows between asynchronous interconnections instead of long-distance transmission. Historically, the most commonly used HVDC transmission technologies were based on lone-commutated thyristor converter topologies also called current source converter (CSC) HVDC. During the last two decades, the voltage source converter (VSC)-based HVDC systems started to become an increasingly attractive technology and started to be used in many HVDC transmission projects worldwide. VSC converters use insulated gate bipolar transistor (IGBT) technology, allowing many benefits, such as independence on grid characteristics at both ends of transmission, better power quality, fast bidirectional power flows with independent control over active and reactive power, operation in weak AC networks, and ability to provide resiliency services in the form of black start. Another advantage of VSC HVDC transmission is capability of multi-terminal operation; however, this feature has been implemented only in few projects worldwide, due to difficulties in realizing DC protection in multi-terminal DC grids. HVDC transmission needs to be designed with proper protection to withstand and ride through faults that can occur in DC links and in AC networks at both sending and receiving ends of HVDC interconnectors. The converter terminal topology has a large impact on fault ride-through (FRT) capabilities. The control strategies employed in converters are also important for DC FRT. AC FRT capabilities are less dependent on converter topologies; however, care must be taken to avoid dangerous increases in DC link voltage levels and also current and voltage stresses on switching devices. One method of protecting DC-link from overvoltage during AC faults is use of crow-bar circuits, so short-term loading can be provided during AC fault at the receiving end thus avoiding line unloading and consecutive DC voltage rise. Another important aspect of HVDC interconnector operation is an impact on power system stability at both ends. The stability of interconnected power systems utilizing VSC HVDC transmission can be considerably improved by the use of controls enabling HVDC converters to provide various types of essential reliability services at both ends of the interconnector link.

\section{Resilient Energy Platform}

The Resilient Energy Platform helps countries address power system vulnerabilities by providing strategic resources and direct country support to enable planning and deployment of resilient energy solutions. This includes expertly curated reference material, training materials, 
data, tools, and direct technical assistance in planning resilient, sustainable, and secure power systems. Ultimately, these resources enable decision makers to assess power sector vulnerabilities, identify resilience solutions, and make informed decisions to enhance energy sector resilience at all scales (including local, regional and national). To learn more about the technical solutions highlighted in this fact sheet, visit the Platform at: https://www.resilientenergy.org.

\section{Resources}

Brancucci Martinez-Anido, Carlo."Electricity Without Borders-The need for cross-border transmission investment in Europe." September 2013. https://repository.tudelft.n//islandora/object/ unid:7eaee878-8ef0-49da-b837-c1 de66c082af?collection=research.

Cox, Sadie, Pieter Gagnon, Sherry Stout, Owen Zinaman Andrea Watson, and Eliza Hotchkiss. "Distributed Generation to Support Development-Focused Climate Action-Emerging Climate Change and Development Topics for Energy Sector Transformation: An EC-LEDS White Paper Series." NREL-TP-6A20-66597. September 2016. https://www.nrel.gov/docs/fy160sti/66597.pdf.

European Commission. "Electricity network codes and guidelines." https://ec.europa.eu/energy/en/ topics/markets-and-consumers/wholesale-market/ electricity-network-codes\#content-heading-0.

European Union. "Internal Energy Market. http://www. europarl.europa.eu/ftu/pdf/en/FTU_2.1.9.pdf.

IPCC (Intergovernmental Panel on Climate Change). Managing the Risks of Extreme Events and Disasters to Advance Climate Change Adaptation. A Special Report of Working Groups I and II of the Intergovernmental Panel on Climate Change. Edited by C. B. Field, V. Barros, T. F. Stocker, D. Qin, D. J. Dokken, K. L. Ebi, M. D. E Enhancing Power Sector Resilience. 103 Mastrandrea, K. J. Mach, G.-K. Plattner, S. K. Allen, M.
McBennett, Brandon, Amy Rose, David Hurlbut, David Palchak, and Jaquelin Cochran. Cross-Border Energy Trade between Nepal and India: Assessment of Trading Opportunities. NREL/TP-6A20-72066. Golden, CO: NREL. April 2019. https://www.nrel.gov/docs/ fy19osti/72066.pdf.

Nordic Energy Regulators. "An overview of the Nordic Electricity Market. https://www. nordicenergyregulators.org/about-nordreg/ an-overview-of-the-nordic-electricity-market/.

RERA (Regonal Electricity Regulators Association of Southern Africa). Guidelines for Regulating Cross-border Power Trading in Southern Africa. April 2010. https://www esmap.org/sites/default/files/esmap-files/P111483. AFR_Guidelines\%20for\%20Regulating\%20Crossborder\%20Power\%20Trading\%20in\%20Southern\%20 Africa_Hughes.pdf.

SMARD. "Cross-border electricity trade." https://www. smard.de/en/wiki-article/5884/6012.

USAID and IRADe. South Asia Regional Initiative for Energy Integration Program Overview. https://sari-energy.org/.

Wang, Xiaoping, Ray Brown, Guillaume PrudentRichard, and Katrina O'Mara. Enhancing power sector resilience:emerging practices to manage weather and geological risks. Energy Sector Management Assistance Program. Washington, D.C.: World Bank Group. June 2016. http://documents.worldbank.org/curated/ en/469681490855955624/Enhancing-power-sectorresilience-emerging-practices-to-manage-weather-andgeological-risks.

Western Energy Imbalance Market. "About." https://www. westerneim.com/Pages/About/default.aspx.

\section{References}

ACER (Agency for the Cooperation of Energy Regulators). Home page. Last modified October 2019.

https://www.acer.europa.eu/en.

BloombergNEF. https://www.bnef.com/login/?r=\%2Fcore\%2Fnews\%2F688717\%253Fe\%253DNews\%252520Watch\%25253Asailthru.

Club of Mozambique. "Malawi-Mozambique secure funding for power interconnection." February 20, 2019. https://clubofmozambique.com/news/malawi-mozam bique-secure-funding-for-power-interconnection/.
Cox, Sadie, Eliza Hotchkiss, Dan Bilello, Andrea Watson, Alison Holm, and Jennifer Leisch. Bridging Climate Change Resilience and Mitigation in the Electricity Sector Through Renewable Energy and Energy Efficiency. NREL/ TP-6A20-67040. Golden, CO: NREL. November 2017. https://www.nrel.gov/docs/fy180sti/67040.pdf.

ESCOM (Electricity Supply Corporation of Malawi Limited). "Transmission Directorate." 2015. http://www. escom.mw/transmission.php.

Jenner, Lynn. "Idai (Southern Indian Ocean)." NASA Hurricane and Typhoon Updates. March 28, 2019. https://blogs.nasa.gov/hurricanes/tag/idai-2019/.

Lamsal, Ramesh. "Nepal Practices Energy Banking; Sends 200 MW Electricity to India." Nepal24hours.com. July 16, 2019. https://www.nepal24hours.com/nepal-practic es-energy-banking-sends-200-mw-electricity-to-india/. Resnick, Brian. "Cyclone Idai:'The scale of devastation is enormous."' Vox. March 19, 2019. https://www.Vox. com/energy-and-environment/2019/3/19/18272950/ cyclone-idai-mozambique-zimbabwe-malawi.

USAID. "Cross-Border Electricity Trade," SARI/ El. https://sari-energy.org/program-activities/ cross-border-electricity-trade/.

USAID. Power Africa Transmission Roadmap to 2030: A Practical Approach to Unlocking Electricity Trade. November 2018. https://www.usaid.gov/sites/ default/files/documents/1860/PA_Transmission_ Roadmap_508.pdf.

The World Bank. "Access to electricity (\% of population)." https://data.worldbank.org/indicator/eg.elc.accs.zs.

\section{www.resilient energy.org | www.nrel.gov/usaid partnership}

Jennifer E. Leisch, Ph.D.

USAID-NREL Partnership Manager

U.S. Agency for International Development Tel: +1-303-913-0103 | Email: jleisch@usaid.gov

\section{Sadie Cox}

Senior Researcher

National Renewable Energy Laboratory

Tel: +1-303-384-7391 | Email: sadie.cox@nrel.gov

This work was authored, in part, by the National Renewable Energy Laboratory (NREL), operated by Alliance for Sustainable Energy, LLC, for the U.S. Department of Energy (DOE) under Contract No. DE-AC36-08GO28308. Funding provided by the United States Agency for International Development (USAID) under Contract No. IAG-17-2050. The views expressed in this under Contract No. IAG-17-2050. The views expressed in this
report do not necessarily represent the views of the DOE or the report do not necessarily represent the views of the DOE or
U.S. Government, or any agency thereof, including USAID. NREL/TP-6A20-75153 | December 2019
The Resilient Energy Platform provides expertly curated resources, training, tools, and technical assistance to enhance power sector resilience. The Resilient Energy Platform is supported by the U.S. Agency for International Development.

The USAID-NREL Partnership addresses critical challenges to scaling up advanced energy systems through global tools and technical assistance, including the Renewable Energy Data Explorer, Greening the Grid, the International Jobs and Economic Development Impacts tool, and the Resilient Energy Platform. More information can be found at: www.nrel.gov/usaid-partnership.

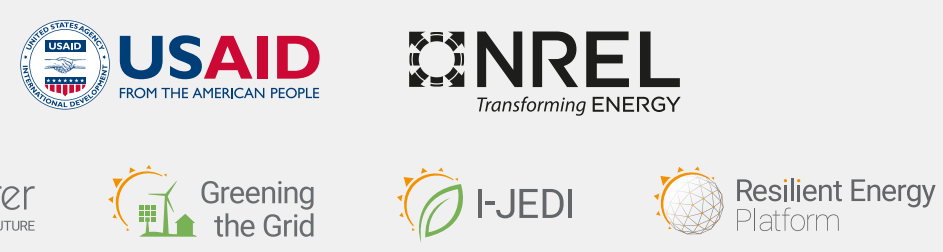

